$$
\begin{array}{r}
\text { Marc Hansmann } \\
\text { Vor dem dritten Staatsbankrott? }
\end{array}
$$




\section{Zeitgeschichte im Gespräch Band 13}

Herausgegeben vom

Institut für Zeitgeschichte

Redaktion:

Bernhard Gotto, Andrea Löw und Thomas Schlemmer 


\title{
Vor dem dritten Staatsbankrott?
}

\author{
Der deutsche Schuldenstaat \\ in historischer und internationaler \\ Perspektive
}

von

Marc Hansmann

2., durchgesehene Auflage

Oldenbourg Verlag München 2012 
Bibliografische Information der Deutschen Nationalbibliothek

Die Deutsche Nationalbibliothek verzeichnet diese Publikation in der Deutschen Nationalbibliografie; detaillierte bibliografische Daten sind im Internet über http://dnb.d-nb.de abrufbar.

Titelbild: Berlin (Mitte) - Schuldenuhr Quelle: ullstein bild

(C) 2012 Oldenbourg Wissenschaftsverlag GmbH, München Rosenheimer Straße 145, D-81671 München www.oldenbourg-verlag.de

Das Werk einschließlich aller Abbildungen ist urheberrechtlich geschützt. Jede Verwertung außerhalb der Grenzen des Urheberrechtsgesetzes ist ohne Zustimmung des Verlages unzulässig und strafbar. Dies gilt insbesondere für Vervielfältigungen, Übersetzungen, Mikroverfilmungen und die Einspeicherung und Bearbeitung in elektronischen Systemen.

Konzept und Herstellung: Karl Dommer

Einbandgestaltung: hauser lacour

Satz: Dr. Rainer Ostermann, München

Druck und Bindung: Grafik+Druck GmbH, München

Dieses Papier ist alterungsbeständig nach DIN/ISO 9706

ISBN 978-3-486-71784-6

eISBN 978-3-486-71785-3 
Für Meike 
